\title{
NUMERICAL SIMULATION OF RESIDUAL STRESSES AND DISTORTIONS OF T-JOINT WELDING FOR BRIDGE CONSTRUCTION APPLICATION
}

Prediction of the distortions and residual stresses of the welded steel structures is still very important to reduction of the costs, mainly during the optimization of welding process. If there is necessity of the higher welding current to ensure weld penetration, distortions might be influenced by appropriate welding sequence. During optimization process, numerical analysis of welding process, based on finite element method, can be used to prediction of distortions at different welding sequences without necessity of preparing high amount of experimental samples. Numerical simulation of T-joint welding process is presented in this article, together with verification of the analysis by thermocouple measurements and contactless measurement of distortions.

Keywords: Distortions, finite element method, residual stress, SYSWELD, welding simulation.

\section{Introduction}

Welding distortions in a structure or component can result in the degradation of its dimensional tolerances followed by costly rectifications and possible delays in the production line. Additionally, welding residual stresses can influence the fatigue performance and buckling strength of the product. Therefore, understanding and controlling the formation of weld induced distortions and residual stresses are of the utmost importance in the manufacturing industry [1].

During the last three decades, with the evolution of computing capabilities, the finite element (FE) method has proven itself as an alternative and acceptable tool for prediction of welding residual stresses and distortions. The FE simulations for the welding process can be divided into three categories, though they all have a common motive which is assessment of welding residual stresses and distortions. The three categories are as follows:

1. The simulations in which the influence of welding process specifications (heat input, plate thickness, weld sequence etc.) are investigated.

2. The simulations in which a novel numerical strategy is used to get the results with acceptable accuracy but with less computational time.

3. The simulations in which FE input parameters (mesh size, element type, heat source model, material properties and material models etc.) are manipulated to study their influence on residual stresses and distortions [1].

Application of the first category allows optimization of the manufacturing process before assembly of the final construction. However, better FE analysis is performed if experimental samples are prepared to verification. Samples can have lower dimensions that are still significant advantage of the numerical analysis. In the article, application of the first FE category to prediction of angular deformations and residual stresses during T-joint welding is presented. Results are verified by thermocouple measurements and contactless deformation measurement.

In principle, a finite element simulation of the welding process consists of two main parts: thermal analysis and mechanical stress analysis. In thermal analysis, the temperature field is determined as a function of time for each integration point. This temperature time-history is used as an input into the thermal stress analysis. Herein, the thermal solution can be sequentially or fully coupled with the mechanical solution of the structure. Because the rate of heat generation due to mechanical dissipation energy can be neglected in the heat transfer analysis, a sequentially coupled thermal-stress analysis is commonly applied for the simulation of a welding process in which a thermal analysis is followed by a stress analysis [2-6].

\footnotetext{
* 'Radoslav Konar, ${ }^{1}$ Marek Patek, ${ }^{2}$ Michal Sventek

${ }^{1}$ Department of Technological Engineering, Faculty of Mechanical Engineering, University of Zilina, Slovakia

${ }^{2}$ MONT IRP, s.r.o., Zilina, Slovakia

E-mail: radoslav.konar@fstroj.uniza.sk
} 


\section{Experimental measurements and results}

Experimental works consisted of the measurements of thermal cycles by the thermocouples and contactless distortions measurement by the TRITOP system.

Each measurement was performed on the T-joint made of $\mathrm{S} 355 \mathrm{~J} 2+\mathrm{N}$ steel plates with $12 \mathrm{~mm}$ thickness welded by the fillet weld from both sides of the web. Welds were prepared by automatic MAG welding process by FastMIG Basic KM500 device at welding parameters according to Table 1. Welding wire INEFIL (G $424 \mathrm{M}$ G3Sil in terms of EN ISO 14341-A) with $\emptyset 1.2 \mathrm{~mm}$ diameter was used as a filler material. During the process, shielded gas consisting of $18 \% \mathrm{CO}_{2}+82 \% \mathrm{Ar}$ was used.

\begin{tabular}{ccccc}
\multicolumn{2}{l}{ Welding parameters } & & & Table 1 \\
\hline Weld & Current & Voltage & Welding speed & Arc power \\
pass & $I_{z}[A]$ & $U_{z}[V]$ & $v_{z}\left[\mathrm{~mm}^{-1} \mathrm{~s}^{-1}\right]$ & $Q\left[\mathrm{~kJ} . \mathrm{mm}^{-1}\right]$ \\
\hline 1 & 421.7 & 41.4 & 5.86 & 2.38 \\
\hline 2 & 394.8 & 39.3 & 5.88 & 2.11 \\
\hline
\end{tabular}

\subsection{Measurements of thermal cycles}

Samples with length of $750 \mathrm{~mm}$ were used during thermocouples measurements. Base plate width was $200 \mathrm{~mm}$ and web was $100 \mathrm{~mm}$ high. Thermal cycles were measured by 9 thermocouples type $\mathrm{K}$, placed in the base plate from the bottom side in three planes ( 3 thermocouples in each plane). Thermocouples were in different depth and distance of the center of the sample to better description of temperature distribution, mainly in heat affected zone (HAZ) of the welds. Position of the thermocouples TC03, TC04 and TC 05 used for the verification of the thermal behavior during experimental measurement and FE analysis is shown in Fig. 1. Temperatures were during welding measured with the frequency of $10 \mathrm{~Hz}$.

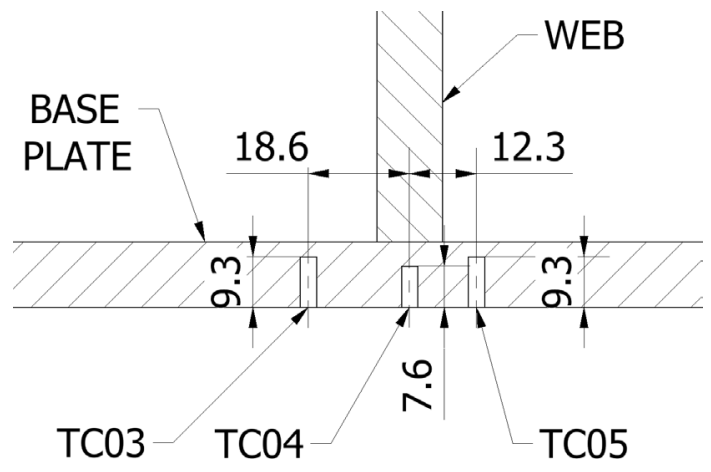

Fig. 1 Position of the thermocouples TC03, TC04 and TC05

Characteristic curve of the thermal cycles measured by thermocouples T03 and T05 placed in the same depth $(9.3 \mathrm{~mm})$ but in different distance of the base plate vertical axis (T03 - $18.6 \mathrm{~mm}$ in $1^{\text {st }}$ weld HAZ, T05 $-12.3 \mathrm{~mm}$ in $2^{\text {nd }}$ weld HAZ) is shown in Fig. 2. Position of the thermocouple TC04 was very close to the weld penetration (see Fig. $8 \mathrm{~b}$ ), which led to destruction of this thermocouple during the welding process. Thermal cycle thus could not be used to verification of the results.

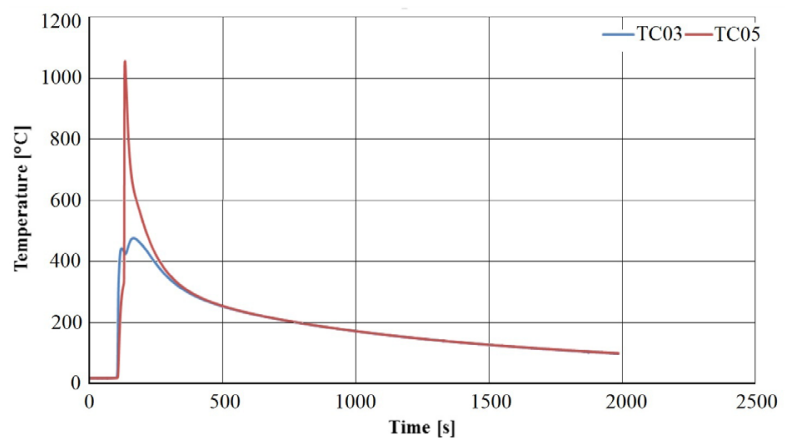

Fig. 2 Characteristic curve of temperature distribution in $H A Z$ of the weld joints

\subsection{Distortions measurements}

Distortions of the T-joint were determined by the displacement of the points placed on the sample by optical measuring system TRITOP. The TRITOP system is an industrial optical measuring system that acquires $3 \mathrm{D}$ coordinates of selected points of a measuring object without contact. In order to carry out photogrammetric measurements, the object needs to be recorded from various directions with a high-end digital camera. It is not necessary to maintain exact camera positions. Some coded measuring markers are applied to the fixture or directly to the object and are used for the automatic evaluation process. Scale bars are positioned next to the object. Their dimensions are transferred to the measurement to provide scale and to observe the measuring accuracy. Surface points to be measured are marked with removable markers or adapters. Photographs prepared by digital camera are after creating processed in the appropriate software.

Experimental samples were during the distortion measurement welded by two welding sequences (Fig. 3). First sequence was consecutive welding with one welding tractor. One fillet weld was prepared at first, and after the tractor was transferred to other side of web, second weld was made. Second sample was welded by two welding tractors at once. The second welding source started to work with technological delay of $25 s$ after the first one. 


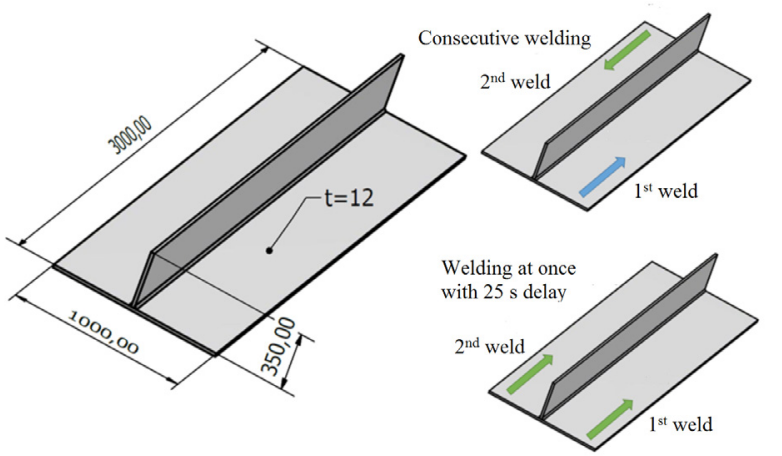

Fig. 3 Dimensions of the sample and welding sequences during distortions measurements

Distortions of the T-joint were processed in the TRITOP software and each point's coordinates were transferred to graphic output of sample distortions. Example of the distortions for second welding sequence (welding at once) is shown in Fig. 4.

Coordinates of the points served for the calculation of the angular distortion by the law of cosines and difference of the computed angles between the web and base plate on the both sides of the T-joint. Angular distortion was computed in the 5 cross-sections, where the $1^{\text {st }}$ one was situated in the front of the sample (beginning of the $1^{\text {st }}$ weld) and the others were placed in intervals $150 \mathrm{~mm}$ long. Calculated angular distortions are shown in Table 2. Positive value represents decreasing (closing) of the angle between the base plate and web, and negative value increasing (opening) of the angle.

\section{Numerical simulation of welding}

FE analysis of welding was prepared to prediction of temperature distribution during welding, distortions and residual stresses after welding.

\subsection{Input parameters}

Due to relatively large dimensions of the experimental samples, simplification of the structure by 2D geometrical model was applied, which represents cross-section of the T-joint. Simplification not only allowed shorter computational time, but also finer meshing in the weld area in relatively low number of the elements. It increases precision of the welding analysis.

Two geometrical models were prepared during analysis to ensure possibility of comparison of the experimental and numerical results (different dimensions of the base plate and web were used in experiments). Dimensions of the model to thermal analysis corresponded with sample from thermocouples

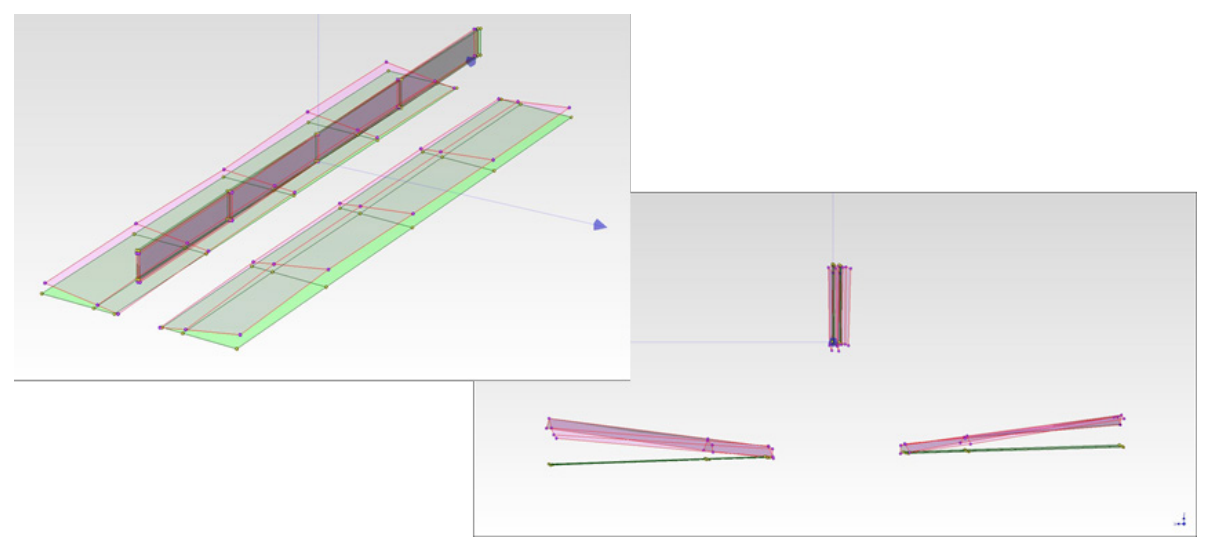

Fig. 4 Distortions of the sample after welding with technological delay $25 \mathrm{~s}$ (green - before welding; red - after welding)

Angular deformation obtained by optical measurement

Table 2

\begin{tabular}{ccccc}
\hline \multirow{2}{*}{$\begin{array}{c}\text { Cross- } \\
\text { section }\end{array}$} & \multicolumn{2}{c}{ Consecutive welding } & Welding at once \\
\cline { 2 - 5 } & Right side (1 ${ }^{\text {st }}$ weld $)$ & Left side $\left(2^{\text {nd }}\right.$ weld $)$ & Right side $\left(\mathbf{1}^{\text {st }}\right.$ weld $)$ & Left side $\left(2^{\text {nd }}\right.$ weld $)$ \\
\hline 1 & $0.7408^{\circ}$ & $-0.8958^{\circ}$ & $1.0180^{\circ}$ & $-0.7137^{\circ}$ \\
\hline 2 & $1.3464^{\circ}$ & $-1.1177^{\circ}$ & $0.6101^{\circ}$ & $-1.0746^{\circ}$ \\
\hline 3 & $1.4745^{\circ}$ & $-1.2073^{\circ}$ & $0.4941^{\circ}$ & $-0.7797^{\circ}$ \\
\hline 4 & $1.5448^{\circ}$ & $-1.3362^{\circ}$ & $0.7777^{\circ}$ & $-0.6003^{\circ}$ \\
\hline 5 & $0.9160^{\circ}$ & $-0.9167^{\circ}$ & $0.7848^{\circ}$ & $-0.4983^{\circ}$ \\
\hline Average & $1.2045^{\circ}$ & $-1.0947^{\circ}$ & $0.7369^{\circ}$ & $-0.7333^{\circ}$ \\
\hline
\end{tabular}


measurement and mechanical analysis model had the same dimensions as distortion measurement sample.

Geometrical model was created in AutoCAD program and consequently meshed in Visual-Mesh software. Thermal source movement was defined by trajectory path and so-called reference that serve to definition of the local coordinate system. Both curves (lines) were formed by 1D elements. Along with weld parts and curves of the thermal source movement, a plane (curve) of heat exchange has to be defined. In the prepared mesh, the curve formed as a contour of the 2D model served for this purpose. Final model of the T-joint was formed by $27842 \mathrm{D}$ elements and 802 1D elements (Fig. 5).

Mechanical properties of the FE model were defined by material database of SYSWELD software for S355J2G3 steel. Since material used in experimental measurements had the same strength grade as material in software database, it was not necessary to modify the database.

Welding process is in numerical simulations defined by heat source model. Arc welding processes (MMA, MIG/MAG, TIG, etc.) are mostly defined by double-ellipsoidal heat source (so-called Goldak's source) [1,2 and 4]. Geometry and heat source parameters of the double-ellipsoid that was defined according to macrograph of the experimental sample and real heat input are shown in Fig. 6 and Table 3.

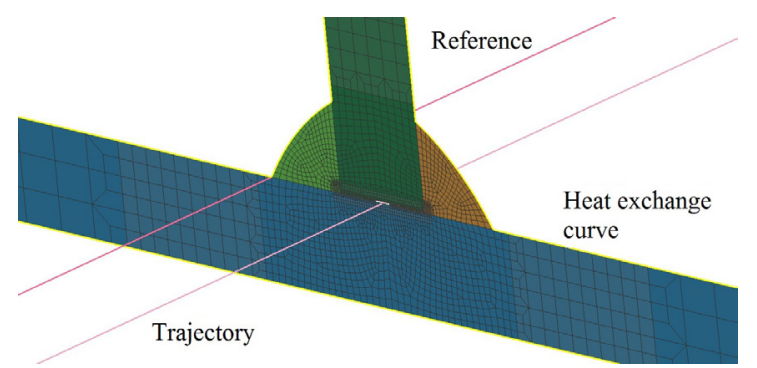

Fig. 5 FE mesh

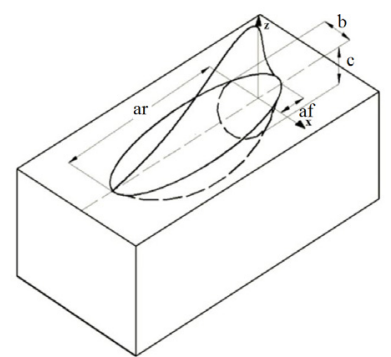

Fig. 6 Geometry of double-ellipsoidal heat source model [1,2,4]
Welding speed of the heat sources corresponded with speed during experimental measurements (shown in Table 1).

During welding, a considerable amount of heat is lost by radiation and convection, while radiating loses are dominating at higher temperatures near the weld zone and convection loses are significant at low temperatures away from the weld line. In this analysis, radiation is modeled by standard Stefan-Boltzman relation, in which the main parameter is radiation emissivity $\varepsilon$ [7]. Constant value of the emissivity was maintained with the value of $\varepsilon=0.8$ that corresponds value with oxidized surfaces of materials [8]. Heat loss by convection depends on convective heat transfer coefficient, or on heat flux $q$ [7]. In performed analysis, constant heat flux was defined with the value of $8 \mathrm{~W}^{-2}$. Applied heat flux value was controlled according to cooling curve measured by thermocouples.

Mechanical analysis requires except of the material properties, heat source definition also definition of the clamping conditions. In FE analysis, clamping was defined by removing of the freedom degrees for the two points according to Fig. 7.

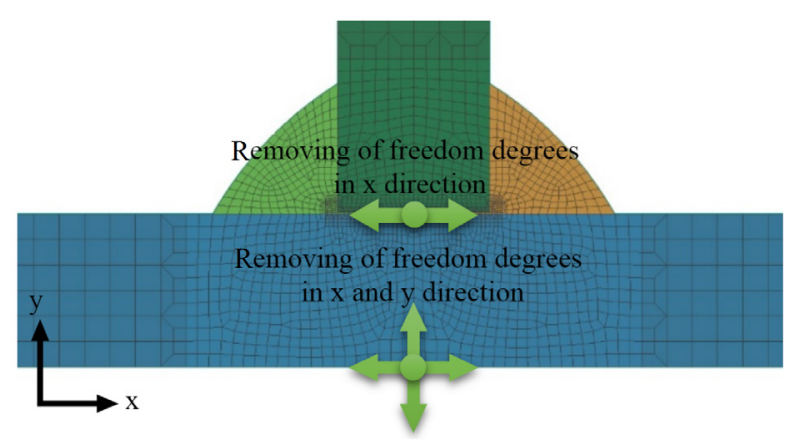

Fig. 7 Clamping conditions of FE analysis

\subsection{Thermal analysis results}

Results of the thermal analysis are thermal fields and thermal cycles during welding. Comparison of the thermal fields and weld joint macrograph from thermocouples measurement is shown in Fig. 8.

Temperature distribution from the FE analysis of welding corresponds with the liquid metal penetration during welding from the macrograph. Slight differences might be observed in the upper part of the welds caused by the shape of the heat source model that does not allow widening of the thermal field in the

Heat source parameters

Table 3

\begin{tabular}{ccccccccccc}
\hline Bead & $\begin{array}{c}Q_{f} \\
{\left[\mathrm{~W} \cdot \mathrm{mm}^{-3}\right]}\end{array}$ & $\begin{array}{c}Q_{r} \\
{\left[\mathrm{~W} \cdot \mathrm{mm}^{-3}\right]}\end{array}$ & $\begin{array}{c}a_{f} \\
{[\mathrm{~mm}]}\end{array}$ & $\begin{array}{c}a_{r} \\
{[\mathrm{~mm}]}\end{array}$ & $\begin{array}{c}b \\
{[\mathrm{~mm}]}\end{array}$ & $\begin{array}{c}c \\
{[\mathrm{~mm}]}\end{array}$ & $\begin{array}{c}x_{0} \\
{[\mathrm{~mm}]}\end{array}$ & $\begin{array}{c}a_{y} \\
{\left[{ }^{\circ}\right]}\end{array}$ & $y_{0}[\mathrm{~mm}]$ & $z_{0}[\mathrm{~mm}]$ \\
\hline 1. & 18.62 & 14 & 2 & 4 & 5.5 & 9.4 & 8 & -49 & 0 & -2.2 \\
\hline 2. & 12.635 & 9.5 & 2 & 4 & 7.5 & 10 & -8 & 56 & 0 & -2.8 \\
\hline
\end{tabular}



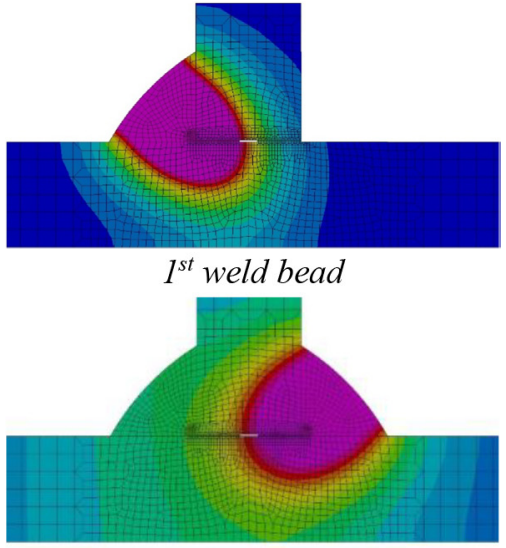

$2^{\text {nd }}$ weld bead

a) thermal fields

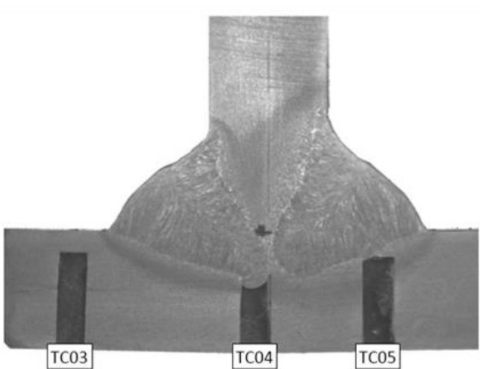

b) weld macrograph

Fig. 8 Thermal fields of the first and second weld bead in comparison with macrograph of weld joint after consecutive welding

Parameters of thermal cycles after experimental measurements and FE analysis

Table 4

\begin{tabular}{cccccc}
\hline $\begin{array}{c}\text { Thermocouple } \\
\text { (FE node) }\end{array}$ & Exp. / Sim. & $\boldsymbol{T}_{\max }\left[{ }^{\circ} \mathrm{C}\right]$ & $\boldsymbol{t}_{8 / 5}[\boldsymbol{s}]$ & $\boldsymbol{r}_{300}\left[{ }^{\circ} \mathrm{C.s}^{-1}\right]$ & $\boldsymbol{t}_{100}[\boldsymbol{s}]$ \\
\hline \multirow{2}{*}{$\mathrm{TC} 03$} & Exp. & 476 & - & 0.52 & 1798 \\
\cline { 2 - 6 } & Sim. & 462 & - & 0.85 & 1804 \\
\hline \multirow{2}{*}{ TC05 } & Exp. & 1055 & 64.8 & 0.54 & 1842 \\
\cline { 2 - 6 } & Sim. & 1297 & 40.5 & 0.86 & 1837 \\
\hline
\end{tabular}

outer part of the weld. Thermal cycles were obtained in the places of corresponding with the thermocouples position, from which the characteristic parameters of the cycle (maximal temperature - $T_{\max }$, cooling time from $800{ }^{\circ} \mathrm{C}$ to $500^{\circ} \mathrm{C}-t_{8 / 5}$, cooling rate in $300{ }^{\circ} \mathrm{C}-r_{300}$ and cooling time from $T_{\max }$ to $100{ }^{\circ} \mathrm{C}-t_{100}$ ) were defined and compared with those obtained by experimental measurements (Table 4).

\subsection{Mechanical analysis results}

Values of the angular distortions were computed from the displacements of the nodes placed on the edges of the planes and with application of the law of cosines, similarly to experimental measurements. Results of the angular distortions are shown in Table 5.

Angular distortions obtained by numerical analysis

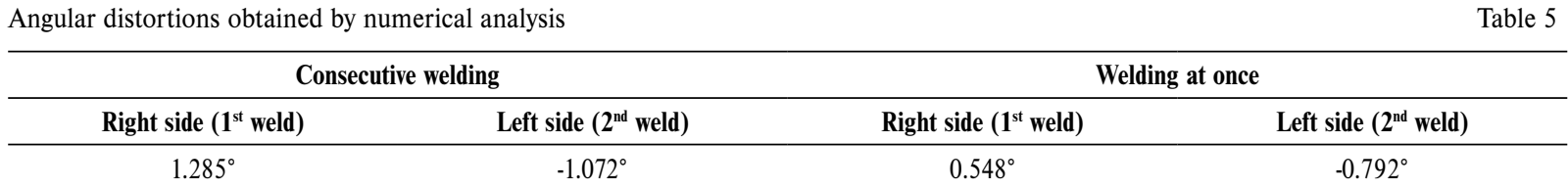

\section{Discussion}

Temperature cycles obtained by numerical simulation achieved high agreement with the experimentally determined curves. The highest agreement was at the cooling time from the maximum temperature to $100{ }^{\circ} \mathrm{C}$, where the differences were lower than $1 \%$. High match was also in the maximum temperature of the cycle, but with increasing temperature the agreement decreased. It can be caused by even slight differences in actual and computational thermal conductivity of the material, but also by imperfect coupling of the thermocouple to the material or the position of the thermocouple in the hole (ceramic cover of thermocouple in the hole acts as a place with different thermal properties as welded material). Higher differences were found in the parameters $t_{8 / 5}$, and $r_{300}$ that are significantly influenced by real heat losses from the material. Only constant values of thermal emissivity and heat flux was applied, but some authors recommend temperature dependent parameters [9]. Simplification of the heat transfer process might result to obtained 
differences of cooling parameters. High agreement of maximum temperature of the cycle and cooling times along with the shape of temperature fields corresponding with the macrostructure are still sufficient conditions for the prediction possibility of residual stresses and distortions.

In the T-joints welding an angular distortion has an important role that is in addition to the welding parameters also related to the welding sequence. Welding parameters have to be in some cases higher to ensure weld penetration. In this case, it is possible to reduce deformation of the plates by application of different welding sequences, to the choice of which it is also possible to use numerical simulation. In the experimental measurements and FE simulations were used two welding sequences with the same welding parameters. Lower distortions were experimentally measured and also numerically predicted in the welding at once with a delay of $25 \mathrm{~s}$. Results of the simulation were in very high agreement with the experimental results for both welding sequences.

\section{Conclusions}

Results obtained by the numerical simulation of the T-joint with subsequent verification by experimental measurements might be concluded as follows:
1) Numerical simulation of welding offers a possibility of high agreement of the thermal cycles and parameters $T_{\max }$ and $t_{100}$ with experiments without a necessity of material database modification according to real chemical composition and without temperature dependent thermal emissivity and heat flux if steel with corresponding strength grade is used.

2) Angular distortion obtained by FE analysis achieves high agreement with experimental results in the application of $2 \mathrm{D}$ FE model.

3) Experimental and simulated results showed lower angular distortion of the T-joint in the welding at once with the 25 $s$ delay compared to consecutive welding by one welding source around the sample.

Numerical analysis with the parameters used in this article can be further applied to distortion prediction of the steel structures with larger dimension and at different welding sequences.

\section{Acknowledgement}

This work has been supported by Scientific Grant Agency of Ministry of Education of the Slovak Republic, grants VEGA 1/0610/12 and KEGA 034ŽU-4/2015. Authors acknowledge the grant agency for support.

\section{References}

[1] BHATTI, A. et al.: Influence of Thermo-mechanical Material Properties of Different Steel Grades on Welding Residual Stresses and Angular Distortion. Materials and Design, 65, 2015, pp. 878-889.

[2] PERIC, M. et al.: Numerical Analysis and Experimental Investigation of Welding Residual Stresses and Distortions in a T-joint Fillet Weld. Materials and Design, 53, 2014, pp. 1052-1063.

[3] DOPJERA, D., MICIAN, M.: The Detection of Artificially Made Defects in Welded Joint with Ultrasonic Defectoscopy Phased Array. Manufacturing Technology, vol. 14, No. 1, 2014, pp. 12-17.

[4] NOVAK, P., MESKO, J., ZMINDAK, M.: Finite Element Implementation of Multi-pass Fillet Weld with Phase Changes Phased Array. Manufacturing Technology, vol. 13, No. 1, 2013, pp. 79-85.

[5] FABIAN, P., JANKEJECH, P., KYSELOVA, M.: Simulation of Roundness, Hardness and Microstructure of Bearing Rings with thin Cross Sections by using SYSWELD, Communications - Scientific Letters of the University of Zilina, vol. 16., No. 3A, 2014, pp. 124-129.

[6] KIK, T. et al.: Numerical Simulations of Heat Treatment Processes. Applied Mechanics and Materials, vol. 809-810, 2015, pp. 799-804, doi:10.4028/www.scientific.net /AMM.809-810.799.

[7] SYSWELD Engineering Guide to Training and Toolbox. France: ESI Group, 2006.

[8] POIRIER, D.R, GEIGER, G.H.: Transport Phenomena in Materials Processing. The Minerals Metals and Materials Society, 1994.

[9] MICHALERIS, P., DEBICCARI, A.: Prediction of welding distortions, Welding J., vol. 76, 1997, pp. 172-181. 